Vol. 1, No. 2

Vitoria - ES, Jun - Dec. 2004

DOI: http://dx.doi.org/10.15728/bbr.2004.1.2.4

p. $118-135$

\title{
Beyond Budgeting: any chance for management improvement?
}

\author{
Fábio Frezatti \\ University of São Paulo
}

\begin{abstract}
This study makes a comparative analysis of the discussion points brought up by Hope and Fraser in questioning what they call the "traditional" company budget format, with a view to identifying aspects that offer more adequate and effective company management opportunities to organizations. In this sense, the confrontation between both authors and the traditional ones leads to the conclusion that, once again, this discussion deals with a new cycle that tries to recover classic qualitative budget aspects that, once complied with, do not need a new label for the sake of effective company management. Although the approach recommends the possibility of not having an annual budget, strictly speaking, it proposes to emphasize a more strategic discussion, front line participation, greater confidence in managers, periodic result forecasting and elimination of the "fixed contract", among other elements. The critical analysis was divided into two groups so as to distinguish between criticism in relation to budget limitations and that resulting from its inadequate usage. Finally, the authors do not solve some problems that may be caused by the nonexistence of a budget, besides creating other problems that would not exist without the proposal.
\end{abstract}

Key words: company budget, strategic.

\author{
Fábio Frezatti \\ Doutorado em Controladoria e Contabilidade \\ Universidade de São Paulo \\ Adress: Av. Prof. Luciano Gualberto, 908 - \\ Prédo III, Cidade Universitária, 05508900 \\ Sao Paulo, SP - Brazil \\ Email: frezatti@usp.br \\ Telephone: (11) 30915820
}

Agradeço o apoio financeiro da FIPECAFI e do CNPQ. 


\section{INTRODUCTION}

ecycling a concept is something natural that has happened over time. It means $\mathrm{R}$ saying that, after a while, a concept needs to be reconsidered, revised, sometimes broadened and, in some cases, forgotten. Resisting change simply as a way of rejecting new things is a kind of attitude the researcher needs to police. On the other hand, adhering to new trends from the very beginning does not seem to be a very responsible research attitude either. Management instruments, which are composed of various concepts, evolve in their specific characteristics. Technologies succeed one another and the demand for more adequate instruments exerts heavy pressure on managers. In some cases, this occurs because the conceptual proposal did not fully attend to a given demand. This is illustrated by the evolution of accounting in dealing with intellectual capital, ecology, etc. On the other hand, examples can be found of concepts presented to the community which clearly result much more from refined existing concepts, methods and models than from a significant rupture or novelty properly speaking, such as EVA, ABM, BSC, among others. This means saying that significant changes in activity management can be demanded or even offered on the basis of changed resources (particularly information technology), assuming the form of people's behavior in organizations (in the sense of participation and empowerment) and even models and tools. In many cases, this is a significant evolution that offers contributions to support managers. This occurred in the financial area as a whole, in management and financial accounting in various aspects.

On the other hand, we can find pure "marketing campaigns" supporting "fashions" concepts that provide consulting business with a financially interesting branch, giving researchers a strange feeling due to the lack of correspondence between research, application and result measurement in a methodologically acceptable way. For sure, the fashion market is wide and very profitable for many companies. Thus, the combination between some researchers' skepticism and, in some cases, lack of good will in terms of changes and new views collides with the willingness of eager consumers, who frequently accept novelties instantaneously, without questioning or even considering the adequacy of the cost-benefit relation. Both attitudes are equally dangerous for knowledge progress.

The specific characteristics found in business planning and its developments are evident, covering the evolution of strategic planning and strategy itself for example. In this sense, the budgetary process, which is clearly subordinated to the elaboration of the strategic view, was presented as something extremely objective and recommended as an essential element of organizational control. Over time, some kinds of criticism have been presented, among which distinct levels and degrees of complexity can be perceived. Among various kinds of criticism that were identified, three groups can be highlighted, which were privileged throughout this study (Hope e Fraser, 2003: 197):

- The budgetary process is very consuming, very expensive and adds little value for the users;

- It is disconnected from the competitive environment and economic information; and

- Encourages dysfunctional and non-ethical behavior.

In this sense, with a view to dealing with criticism about the usefulness of the budget instrument, the approach known as Beyond budgeting is presented as an adequate alternative 
for the problems mentioned above. It is quite aggressive and critical, going as far as to recommend the elimination of companies' annual budget. For the sake of effective discussion, the question guiding this study is: Does Beyond budgeting offer an alternative for the company budget as we know it, that is, the so-called traditional budget? Our analysis is developed as an essay and considers the following steps, which will be detailed throughout the text:

- Choice of adequate gurus. This is about identifying the experts who guide opposite versions. In general terms, this aspect did not require a lot of effort, since Hope and Fraser are the most significant names in terms of Beyond budgeting, while Glenn Welsch, Horngren et al and Hansen and Mowen constitute references for the traditional budget process view;

- Identification of criticism, formulated proposals and analysis of their possible effectiveness in terms of eliminating the problems experienced through the existence of a budget;

- Analysis of proposed benefits and new distortions created by the new view; and

- Conclusions drawn from the analysis.

\section{LIMITATIONS AND DEFICIENCIES OF THE TRADITIONAL COMPANY BUDGET}

For the sake of obtaining a pluralist view, various authors were considered with various approaches to the theme:

- Hansen \& Mowen (1996: 698-699) recognize that the budget exerts a strong impact on executives' career development, bonuses and promotions. Thus, the budget may have an impact on the participants' behavior, which is considered positive behavior when the individual's aims are in consonance with those of the company. This is called goal congruence. However, when administered inadequately, reactions can be negative in several ways, generally culminating in dysfunctional behavior, which means that individual behavior conflicts with the organization. In this sense, the ethics issue stands out. The most critical problems are:

1. definitions of very high or low goals. The desire for challenging and feasible goals is a permanent challenge for managers;

2. overestimation of costs or underestimation of revenues, creating budget reserves, which turns performance demands less objective; and

3. pseudo-participation provoked by subordinates' superficial participation for the mere sake of formal goal acceptance.

The same authors indicate actions that reduce or minimize these dysfunctions, such as: performance feedback, monetary and non-monetary incentives, participation, realistic standards, cost controllability and multiple performance measures. 
- Hope (2000) criticizes:

1. centralization through the budget system. In the quoted author's opinion, this procedure doens't come from the natural coordination but from the coercion emphasis;

2. focus on cost reduction and not on value creation;

3. suffocates initiatives;

4. maintains planning and execution separate instead of approximating them;

5. cost allocation (supposed to be non negotiable); and

6. middle management which insists on being controllers and commanders (sic).

- Hope and Fraser (2003:xviii) complement criticism on what they call the traditional budget process because it:

1. provides poor value;

2. leads to dysfunctional behavior;

3. fails in dealing with fundamental variables of competitiveness; and

4. presupposes absence of confidence.

Hope and Fraser's criticism affects the Balanced Scorecard, which was initially praised (2003: 9) as one of the most innovative recent tools, but which is oriented towards short-term indicators, used in the annual budget.

- Fisher (2002), mentions the following criticism and considers that:

1. budget is a waste of time, since people spend their time on budget follow-up, talking about the past, about what happened versus what had been planned, while it is important to discuss the future. This author obviously ignores that an agreement about the future is exactly what the budget follow-up process tries to accomplish. It is as if the author wanted to say that he does not want to be charged;

2. the budget process does not encourage people's performance but the budget's performance (!!??); and

3. budget revision takes time and companies do not manage to do it rapidly.

- Horngren (2000: 187) highlights the mentioned aspects about inadequate use of the instrument in relation to the under- and overestimation that allow for goals which are relatively easier to reach. As an alternative, he offers Kaizen budgeting, which incorporates continuous improvements verified during the planning process.

Hope and Fraser (2003:xvii) recognize that the problems mentioned in their book come from the way they are executed. They also accept that the budget can be developed at different participation levels (2003: 11) and believe that the instrument allows executives to maintain control on business divisions and units. However, these authors mention that, in the wrong hands (!?), the contracts provide undesirable and dysfunctional results at all organizational levels. They believe that the blame cannot entirely be attributed to the budget BBR, Braz. Bus. Rev. (Eng. ed., Online), 
process (2003: 14), but to the way it is used. However, they compare the budget process to a virus, which will lead to harmful consequences for the entire organization.

\section{III.MAIN BUDGET PROBLEM CAUSES}

In this topic, the work by Hope and Fraser (2003) will be used as a source of reference. The main problem causes mentioned are:

\section{- The budget is difficult to use/elaborate and too expensive}

In the authors' understanding, the process is long and involves the time of many executives from various company areas. Some companies tried to determine the cost of budget elaboration and figures are astonishing. Ford Motor Company reported about US\$ 1.2 billion per year in budget elaboration/usage expenses.

\section{- The budget is outdated in relation to the competitive environment and no longer} attends to executives' or operational managers' needs

In the past, process participants focused management processes based on return on capital goals and implemented plans for achieving them. Thus, rigid controls resulted in performance according to plans, providing planning, coordination and control on the basis of the corporate center, which adapted the budget to this aim. The most important characteristics at that time were the stockholders' demands for increasing improvements, emphasis on financial capital, stable innovation, prices that reflect costs, client and investor loyalty and regulators ignoring ethical standards. In turn, the most important characteristics experienced nowadays are: stockholders demanding better class (segment) performance, dominant intellectual capital, rapid innovation, prices pushed down by globalization, volatile clients and investors and regulators demanding higher ethical standards. Some entities responded to this demand by putting greater emphasis on planning, using rolling budgets and budgets elaborated each quarter or term, provoking additional budget process work and costs.

The use of the Balanced Scorecard is another alternative found in order to maintain a strategic instead of a budget focus. Nevertheless, as stated by Hope and Fraser, indicators are mainly found in the budget, with a short-term orientation. According to them, in a 2002 research, most of the ratios had a financial connotation. Finally, they point out that the modus operandi of the Balanced Scorecard is similar to that of the traditional budget, determining variations.

\section{- The extent of figure manipulation has reached unacceptable levels}

The beginning of budget use in profit entities can be found in the 1920's, when a series of industrial companies started using it in practice (Du Pont, General Motors, ICI and Siemens). In the 1960's, the view of what Hope and Fraser called "fixed contracts" was introduced, that is, goals valid for the budgeted period. In the 1970's, growing accounting dominance was perceived in the sense of income control, accompanied by a lack of attention to production, technology and other activities that determine market competitiveness. In addition, executive education itself emphasizes management through accounting figures. All of these factors lead to increased use of fixed contracts on the basis of commitment between bosses and subordinates. The contract considers the following ingredients: 
○ fixed goal, incentive or bonus;

- a plan acceptance process throughout the entire organization, on the basis of the negotiation between bosses and subordinates;

o commitment towards inter-area actions; and

○ timetable for reports.

A sequence of financial comments is made, which affect the authors' analysis and may be interpreted in different ways:

- the budget has been hijacked by financial engineers, who have used it as a remote control for managing by figures (2003: xviii); and

- attempt to justify Enron and WorldCom as resulting from budget usage by quoting the former CEO of Enron (2003: 12), who said "You have got a budget and you can obtain results at about $2 \%$ below budget. Nothing less is acceptable". Hence, according to these authors, the budget makes executives practice fraud (...), or also "budget tolerance".

A healthy management process must provide the necessary conditions for setting out and directing the most important aims (Hope and Fraser, 2003: 15), which are related to stockholders, maintaining the best collaborators, being innovative, operating within a low cost level so as to satisfy client profitability, maintaining effective governance and promoting ethical reports.

\section{IV..BEYOND BUDGETING: A BIT OF HISTORY AND WHAT IT CONSISTS OF}

In the scenario of interactions among various characters, Dr. Jan Wallander comes up, an executive who was nominated $\mathrm{CEO}$ at Svenska Handelsbanken, a traditional European institution that had abandoned the so-called traditional central planning model some time before. According to Hope and Fraser (2003), the company abandoned budget in 1972 due to dissatisfaction with undesirable effects it provoked. Another case mentioned is Rhodia, a well-known multinational of French origin, who abandoned budget in 1999, after Borealis, a Danish company, had done the same in 1995.

Recently, Wallander has presented an approach known in literature by the expression Beyond budgeting, which characterizes a flexible management process, without the existence of an annual income budget. This approach was applied to the mentioned Scandinavian bank Svenska Handelsbanken, which has been very successful in managing its business for more than 25 years (Hope, 2000), presenting positive results, although not higher than the competition's.

Every researcher who introduces a new approach considers its entry into an environment in which the existing approach is called TRADITIONAL. Wallander did not behave differently and the so-called traditional approach, although not specified by him or other authors, includes all possible tendencies that use the annual budget, which mixes up entities in different development stages, application of concepts with different levels of appropriateness and different perceptions about the instruments. 
The effort structured to provide answers for dissatisfaction about budget, which was considered a very rigid instrument, started in a group of executives from multinational organizations, who were supported by consultants. These meetings, which were held from 1997 onwards (Hope, 2003:xiv), created research carried out in a diversified group of companies in terms of sectors and nationalities. The study focus was based on three questions:

1. Does there exist any alternative for budget?

2. Does there exist any management model?

3. Which lessons can be drawn from its implementation?

The evolution of this meeting culminated in the approach that is now known as Beyond budgeting, which proposed to specify a management format without the existence of an annual organizational budget. It is based on the idea that there should be flexibility for managers, which is achieved on the basis of negotiations, high level of participation by "front line" professionals" and the development of the planning and execution stages by the same actors. Hope and Fraser's leadership is perceived through their book, articles, a site and even a commercial organization that practices and reproduces the approach as a product. Using Hope and Fraser's approach (2003: xix), Beyond budgeting is not a tool to fix some kind of budget problem or something like that. According to the authors, it is about a group of alternative processes that support goals and recognitions, continuous planning, required resources, dynamic coordination of the whole company and a significant group of multilevel controls. It does not demand an annual negotiation process, which culminates in fixed goals and demands greater confidence among participants, focusing on the relation between senior executives and company management.

The following ingredients are treated in the approach (Hope and Fraser, 2003:70):

\section{- Goal definition}

Considers external benchmarking from a medium-term perspective. Means saying that there are not fixed goals but variable ones, resulting from the moment experienced by managers. Intends to eliminate annual fixed measures in order to live with a situational approach.

\section{- Motivation and bonuses}

Bonuses based on external goals with ex-post evaluation, considering what should be done. This view aims to reduce what the authors call "budget tolerance", in the sense of reaching fixed goals at any cost, even if this means giving up ethical principles.

\section{- Strategic process}

Continuous, decentralized and even local process that must be stimulated in view of ambition levels and rapid responses.

- Resource management

The resources are offered upon demand, reducing losses, waste and unnecessary spending. Intends to eliminate issues like "I have to spend it so that I do not lose next year's funds".

\section{- Coordination}


View that "a team" or "being in the same boat" encourages cooperation and service excellence.

- Measuring and control

Rapid and available information focused on learning and encouraging ethical behavior.

Throughout the proposal, some principles are offered (Hope and Fraser, 2003: 70-92), paying special attention to:

- Defining practical and achievable goals related to improvement, without any link with performance evaluation and bonuses. In the authors' work, it does not seem very clear how this is accomplished.

- Performance evaluation and bonuses based on relative improvement contracts, considering what should be done, differently from the traditional view, which establishes the goal in advance and compares it to the actual result in a later stage.

- Turning action plans into a continuous improvement process.

- Making resources available when necessary.

- Coordinating joint actions in the organization according to client demands.

- Basing controls on effective governance and relative performanceindices. 
If the annual budget no longer exists, what kinds of differences will be verified in company management? Hope and Fraser provide a detailed comparison of some management elements that allow us to understand changes in the proposal $(2003: 27)$ :

\section{TABLE1}

\section{Description}

Goals

Rewards, bonuses

Plans

Resources

Coordination

Controls

\section{Comparative company budget elements}

Traditional budget

Goals are fixed annually.

Executives receive them as long as they fit into goal target levels

Fixed goals (fixed contracts) are related to plans

Those resources are made available whose availability to support operational and capital budgets is accepted

Activities will be coordinated with other plan managers according to plans accepted or redirected by a superior level

Performance monitored on a monthly basis and any significant variation must be revised.

Forecast demanded every quarter.

\section{Beyond budgeting}

Goals are not fixed but continuously monitored against a given and preferably external benchmarking, negotiated with the group of managers.

Confidence about receiving rewards exists on the basis of the evaluation by the group of managers, which analyzes performance according to the "what should be done" approach.

Confidence exists that any action can be demanded with a view to reaching mediumterm goals accepted by the management group, within governance principles and strategic parameters of the organization

Confidence exists that resources will be provided when necessary.

Confidence is delegated for the manager to coordinate activities on the basis of periodical agreements and client demands

Confidence exists that the forecast is based on the most probable alternative, so that interference will only occur if the indices' trend lies outside certain parameters.

Source: Hope and Fraser, 2003: 27 


\section{V.NEW CONTRIBUTIONS FROM THE BEYOND BUDGETING APPROACH}

Coherently, Hope and Fraser (2003) want their proposal to be able to answer the three criticisms that were uttered. In this sense, they proclaim that the benefits of their view are (2003: 198-208):

- About being simple, low cost and relevant for users

The authors' arguments consider that:

- Adaptive and decentralized management results in authority and the ability to take rapid decisions in the markets, granting the conditions to answer demands appropriately.

- The fact that no annual budget is developed implies work and cost reduction. On the other hand, professionals involved start dedicating their time to nobler activities, changing the model focus from centralized in terms of control to decentralized for each locality. Thus, teams start engaging in planning and control.

- Leadership gets benefits since more time becomes available for staff-orienting activities.

\section{- About dealing with factors of success in the information economy}

The authors consider that sustainable growth is directed by the following drivers, which are:

\section{- Innovative strategy}

Focus on long-term value creation. For this sake, among various important elements, one key factor is the availability and maintenance of the best professionals, which, in the authors' opinion, requires actions to estimate their creative ability. This may occur in a free and autonomous environment.

The combination between continuous innovation and fixed budgets is difficult and would be facilitated by a freer and more creative environment.

\section{- Low costs}

The demand for cost reduction is permanent and should not only be top-down in the organizational structure, which limits its potential range. It is expected that, once other hierarchical layers were involved, professionals would feel they empowered and would be committed to results to a greater extent.

\section{- Client loyalty and profitability}

When knowing client needs, they will be attended to adequately without pressure to reach goals, which should provoke improvements in the long-term relationship itself.

\section{- Ethically structured reports}

This aspect is dealt with in the framework of encouraging good governance and ethical behavior. In short, opening up completely for information disclosure is a critical part of the process. 
- Encouraging good governance and ethical behavior

It starts from the principle that people want to work in and with more honest organizations and hope for a better balance between professional activities and private life. They want to know the company's situation and where it is going. They want to trust people and be part of a team. The point is that not many organizations are able to offer such perspectives. In the authors' opinion, the nonexistence of pressure towards fixed goals allows for improvements in ethical behavior. Disclosure and transparency are key practices for encouraging good governance.

\section{VI..THE “TRADITIONAL" PLANNING PROCESS}

Reviewing literature classics is a valuable exercise, which may restore beliefs and create inedited perceptions in a second or third reading, considering different maturity levels that are reached over time. Various approaches are possible, but the elements to be considered will be described so as to influence different perspectives in a complementary way. Welsch (1988:1) defines Profit Planning and Control, which is also called Business Plan by Steiner (1979). This name is currently used more frequently for another, more specific application, indicating the systemic and formalized approach to significant stages of the planning and control functions, involving:

- Development and application of long-term aims for the company;

- Specification of company goals;

- Long-term plan developed in general terms;

- Short-term plan described with a view to accompanying responsibilities. 
The same author considers that control basically proposes to guarantee the achievement of company aims, goals and standards (1988: 40). Figure 1 illustrates the elements that constitute the planning process as a whole.

\section{FIGURE 1}

Profit Planning and control

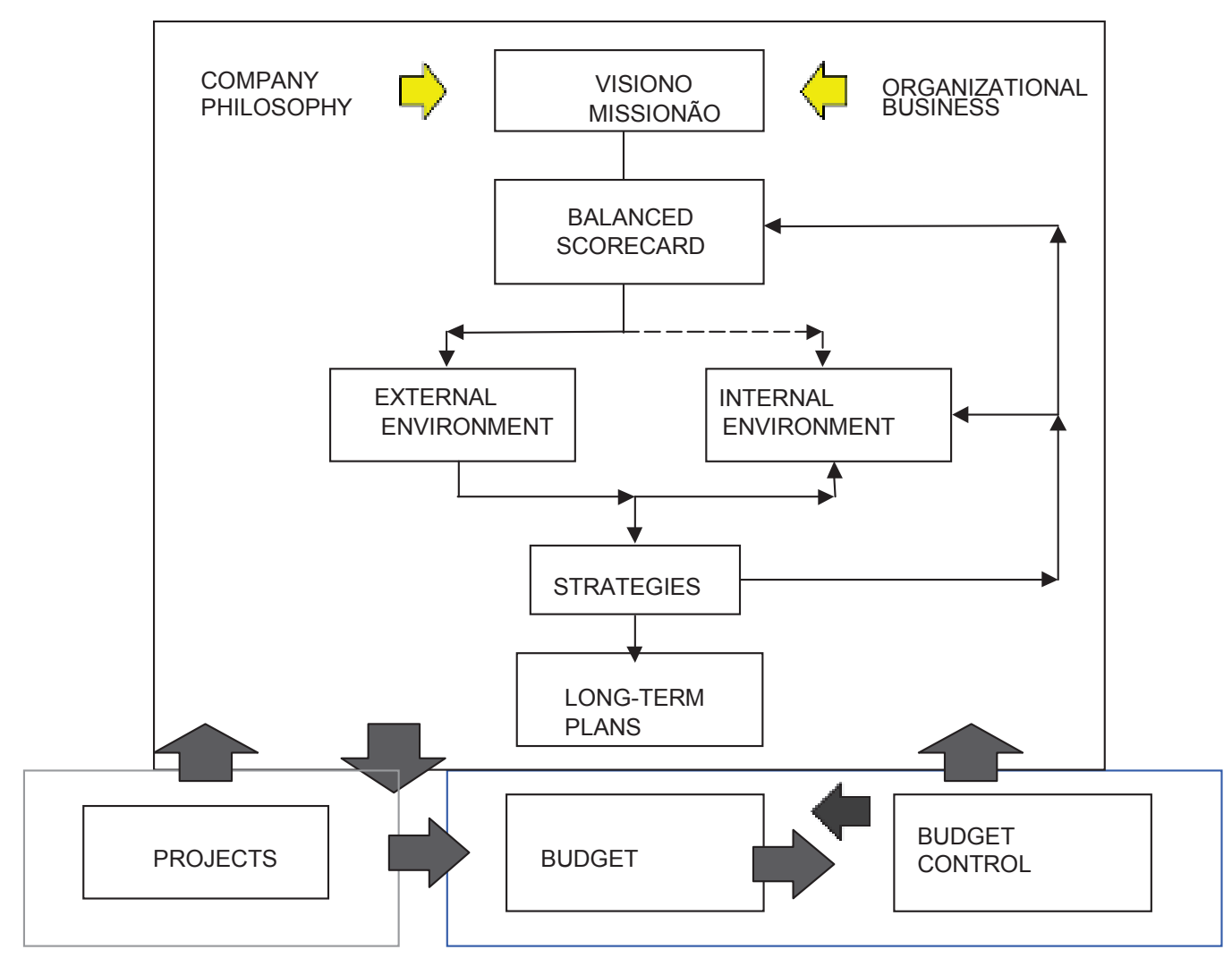

The vision starts the process by making it possible to reach a broad abstraction of the entity's actions, which allows for orientation towards long-term actions. In turn, the mission, which is consistent with the vision, offers conditions for specifying why the organization exists by defining what it does, for whom, how, what kind of social responsibility, etc. The Balanced Scorecard occupies the place of the set of aims the entity defines for its long-term horizon. It allows for a balance among various growth and learning perspectives, internal processes, clients and financial perspectives (Kaplan and Norton, 1996) on the basis of defined indices. The analysis of (external and internal) scenarios identifies opportunities, threats and risks, which in turn create subsidies with a view to defining strategies for the longterm horizon. Long-term plans provide a financial, numerical view of the extent to which strategies may affect company results. At this time, the annual budget comes up, which must implement the decisions taken on the strategic organizational level. In other words, the budget plays a part in the organizational planning process, which is related to different styles of plan execution. What the authors propose is to break up the process by eliminating the annual budget step and, consequently, budget control. 
The hierarchical relation between strategic planning and budget is a structural phenomenon of the process, which has already been treated in literature; however, the intensity level of the efforts made by the organization in the strategic and tactical steps depend on the decision model format, which is adapted to the needs of each organization.

Some terms used in this work may be understood to a broader or narrower extent, which may imply distortion by part of the users. Hence, the following observations can be made about budget and forecast:

- In referring to Atkinson et al (1997), they define budget as the quantitative monetary expression of inflows and outflows with a view to determining if financial planning reaches organizational goals;

- Hope and Fraser (2003) believe the budget consists much more of a management performance process than financial planning. They define budget (2003: 212) as a plan expressed in financial terms, which serves as a basis for performance control, resource allocation, distribution of spending and commitment to financial results;

- Forecast is defined (Hope and Fraser, 2003:214) as the most probable financial result and spending related to a business or project for a specific period of time. The difference in relation to budget is that there does not exist a commitment to reach the goals, which is a fundamental part of the budget concept;

- Hansen \& Mowen (1996: 677) mention that the budget consists of a broad financial plan for the organization as a whole and provides various benefits:

- forces the managers to plan;

- provides informational resources that may be used to improve the decision process;

- supports resource use by defining a standard that will be used subsequently in performance evaluation;

- improves communication and coordination.

In turn, Steiner (1979: 215) observes the planning issue by saying that not a single company made money by making plans, since profit comes from implementing plans. In this sense, with respect to budget, he says that "they are integrated methods for translating the strategic plan into current actions, orienting towards action, defining standards for coordinating actions and establishing the base for performance control, which consists in conformity with plans". The three functions are included in the process: planning, coordination and control (1979:116). Thus, the budget system needs to be adapted to the peculiarities of an organization and the budget must be developed to improve the planning process, since it forces managers to focus their attention on formulating aims and on how they are implemented. On the other hand, budgets demand specifications about what it means to reach them. Finally, a plan in itself does not control anything, but people make plans as wanted. 


\section{VII.CONFRONTATION AND COMPARATIVE ANALYSIS}

The analysis was developed in view of the criticism that gave rise to the proposal, its effectiveness in relation to the planning process as a whole and new problems that are probably created by the Beyond budgeting approach. Criticism can be divided into two groups:

\section{- Inadequate use of the instrument}

- Means saying that the budgeting critics consider that the mentioned aspects are related to how the managers want to use the instrument. The most relevant aspects mentioned are the following:

\section{Over-/underestimation is always present in the elaboration}

These may occur for protecting the agent's interests, for example, due to questions related to uncertainty, or they can even be a step in the learning process. Classic literature recommends feedback as one of the ways of implementing improvements in this kind of distortion over time. Annual budget revision is one possible way of dealing with this question, although these revisions may be perceived as "partial opening up" for changes.

\section{Pseudo-participation by agents}

The managers' greater or lesser interest in participation is part of the entity's cultural mixing and constitutes a compulsory ingredient for developing any kind of management instrument. There are organizations with thousands of employees. How can this be combined with any participative management model? One possible solution is to discuss the meaning of the word participation more flexibly. According to this line of reasoning, putting issues under discussion, offering alternatives and receiving information inside the organization are possibilities for different levels of participation. Thus, although participation is increasingly emphasized, involvement is expected, which can be obtained in various ways, even when a stable annual goal is established. No matter what model is used, the decision agent's tone will be fundamental for turning managers' participation into practice.

\section{Focus on cost reduction and not on value creation}

Actually, this is a limitation in the view of managers who use the model. The model can be used for one of the views as well as for both, to the extent that it guides and provides a view on profit. A goal that is not defined on the occasion of the annual budget and is perceived as adequate afterwards should clearly be incorporated into the instrument and, as consequence, the expenses; the opposite would be the same. This is accordance with the view of the great theoretical reference framework for company budget, which is Glenn Welsch (1988).

\section{Suffocates initiatives}

This may be caused by a management instrument without perspective, whether it is called traditional budget or Beyond budgeting. In other words, it is the level of 
disclosure and involvement at the moment goals are revised that defines the instrument's flexibility and creativity potential.

\section{Centralization of the planning process}

Process decentralization is increasingly implemented. Nevertheless, basic process guidelines and coordination are necessary for efforts to be optimized within the intended time horizon. In some companies, the planning process cannot be as flexible due to their complexity and size.

One criticism against what is called the centralized budget considers that participants do not have the power to define their goals. This view is distorted since participation is an expected ingredient, considered important for the entity's life. On the other hand, the consolidated lack of discussion in a centralized way does not allow for coordinating entities' activities. The question about how to solve the coordination issue is neither clearly nor effectively responded by experts.

\section{Separate planning and execution}

This criticism refers to situations in which other parties than the manager define goals, which will make goals happen. In some dimension, this should not happen through the classical process, on the basis of agents' participation.

\section{Lead to dysfunctional behavior by managers}

The authors quote cases like Enron and WorldCom as examples of situations provoked by the fixed budget, in the sense that people, being forced to obtain results, may adopt unethical attitudes. This debate lacks greater empirical structure and observation since, for validity's sake, we would need to analyze situations of companies with ethical problems which were managed in an extremely flexible and participative way. Ethics goes beyond the instrument, it is located in the managers' head and inadequate usage cannot simply be attributed to it.

\section{Failure in dealing with fundamental variables of competitiveness}

This criticism can be looked at in various ways, one of which considers that executives should pursue goals with an external reference framework, linked up with competition and the market. In this sense, the argument is not valid because the way of structuring variables and the intensity of the challenge will be decided on by managers.

\section{Presupposes absence of confidence.}

In the authors' opinion, defining measures that are not short-term demonstrates a lack of confidence in people. If confidence existed, a priori defined goals would not be necessary. This affirmation is delicate and lacks further research. On the opposite, it can be said that people would not even think about negotiating and defining goals if a previous confidence relation did not exist between agents.

The authors' logic essentially refers to the argument of bad instrument usage. They consider that the fixed performance contract, with variables outside managers' control, leads to undesirable and often unethical behavior (2003: xviii). It can be concluded from this group of elements that the inadequate use of the instrument should not justify not using it. The quoted authors recognize this but perceive the budget as "a virus that has to provoke all of the BBR, Braz. Bus. Rev. (Eng. ed., Online), 
crises" that were mentioned. Mainly because a reasonable part of the elements quoted were expected by classic authors about company budget and actions for eliminating or minimizing them.

\section{- Limitation of the instrument}

Among various criticisms, we can highlight the following:

\section{Costly instrument}

The cost of a management instrument can be verified relatively easily and, according to intentions in terms of precision and range, abstraction criteria can be incorporated. However, the benefit is less tangible and can be analyzed from the perspective of how much is gained by its use as well as how much the absence of a budget would cost. Authors questioning the annual budget have ignored both approaches.

\section{Aggregates little value to the entity or budget is a waste of time}

This aspect was not treated systematically and methodologically. What can be indicated by not aggregating value? The fact that an instrument does not exist can provoke business loss, financial difficulties and non-optimization of results. In itself, a management instrument is a tool, a means for developing actions. If it is possible to do without them, life will become easier and cheaper. Unfortunately, in most cases, they are necessary within a certain scope of action.

\section{Cost allocation (supposed to be non negotiable)}

The existence of cost allocation criteria per business area, result and cost centers are part of the control view and, consequently, transfer prices are verified. Some experts do not resign to the necessary results and control for a given kind of procedure. This problem will exist no matter how the budget is considered.

\section{Middle management insists on being controllers and commanders}

The control perspective is needed since the planning and control approach is part of a whole in which the follow-up and control of variables guarantees the intended result. It is very difficult to avoid this behavior in an environment in which self-control is demanded from areas and people.

5. The budget process does not encourage people's performance but the budget's performance.

As long as it is flexible and revised, the budget process does encourage people to perform. Actually, it is not the budget in itself but how it is used.

\section{Budget revision takes time and companies do not manage to do it rapidly.}

This question is interesting due to the fact that the necessary time and resources for developing the instrument depend on organizational complexity, managers' cultural model and the kind of changes observed.

In turn, Welsch discusses and defends the possibility of having a budget formally (versus informally) and identifies reasons for the budget to be formalized and established in the company (1988: 50-52): 
- The management process cannot completely be developed in a random manner. Planning and control should be developed in a logical, consistent and systematic way;

- As many persons are involved in the management process, the environment must be relatively stable and consistent for people to have credibility;

- Non written aims, plans and goals in terms of probable future results influence the company and frequently turn "half thoughts" or rumors by one or more individuals vague and hard to communicate;

- Effective communication and mutual understanding demand a certain degree of formalization;

- Formalization requires the establishment and observance of a decision, implementation and control timetable;

- Formalization provides the logical base that underlies rational, significant and consistent flexibility in planning and control implementation.

The same author (Welsch, 1988:51) pleads in favor of budget limitations and recommends an approach for the budget to be formalized and established in the company (1988: 50-52):

- Based on estimations;

- Should continuously be adapted to circumstances;

- Budget execution does not occur virtually; and

- The plan does not refer to managers.

\section{FINAL COMMENTS}

It is interesting to perceive how attitudes towards a certain issue can be so different: on the one hand, the Balanced Scorecard intends to provide an instrument, measure, seek compromises and control and, on the other, Hope and Fraser's perspective goes in the opposite direction, proclaiming the elimination of the instrument that seeks to implement organizational strategies. These views apparently result from the authors' different perceptions of entities, corporate cultures and their executives. Thus, in response to the research question, some aspects are disclosed:

- The problems quoted by the Beyond budgeting approach are neither new nor ignored by classical authors who treated the issue before. On the opposite, they are expected and mentioned in literature;

- It is perceived that, in the Beyond budgeting approach, the focus of management lies on the managers and flexibilization. Consequently, the model for having chances of success requires a whole profile of components with abilities and training for action without a control instrument like the budget. Turning the flexible approach operational by means of the budget instrument may compatibilize the entity's needs in a more adequate way, without creating new risks, inherent in excessive flexibility, which are created by the approach proposed above.

- The quoted problems predominantly result from the inadequate usage of the instrument and do not result from the instrument itself; 
- The solutions proposed by Hope and Fraser include recommendations that have already been treated by classic authors;

- Authors offer incipient empirical treatment of findings that are not found in some companies in the form of cases, which may even be considered normal in view of the state of the art.

- Some problems reported on by classic authors were not treated by Hope and Fraser, among which the following stand out:

1. How to control the entity with a high level of flexibility and no controlinstrument?

2. In its original sense, can control be understood as something non-desirable in the entity?

3. How can the short and long terms be coordinated in an organization without an annual budget?

4. How can we know if the entity's performance lies within expectations?

5. How can the course of action be corrected if no standards were defined?

6. Does the managers' commitment to reach goals become a mere demonstration of good will?

The Beyond budgeting view does not only affect the way of dealing with the budget in itself but the entire planning design, the entity's business plan, since different control formats change the structural steps of the organization's business planning. Actually, depending on the company's nature and cultural characteristics, there are different ways of working. The aim is for the model to be coherent, consistent and adequate for the organization's planning needs. So what? Well decide yourself.

\section{REFERENCES}

Fisher, Liz, 2002, One step beyond. Accountancy, p.32-34, March.

Hansen, D.R. and Mowen, M.M., 1996, Cost management: accounting and control. Cincinnati: South Western.

Hope, Jeremy, 2000, Beyond budgeting: pathways to the emerging model. Balanced Scorecard Report. Harvard Business School Publishing, p.3-5.

Hope, Jeremy and Fraser, Robin, 2003, Beyond budgeting: how managers can break free from the annual performance trap. Harvard Business School Press.

Horngren, C., Foster, G. and Datar, S., 2000, Cost accounting: a managerial emphasis. Upper Saddle River: Prentice Hall.

Kaplan, Robert S. and Norton, David P., 1996, Balanced Scorecard: translating strategy into action, Boston: Harvard Business School Press.

Steiner, George A., 1979, Strategic planning: what every manager must know. New York: Free Press.

Welsch, G., Hilton, R. and Gordon, P. N., 1988, Budgeting: profit planning and control, fifth edition, Englewood Cliffs. 